University of Nebraska - Lincoln

DigitalCommons@University of Nebraska - Lincoln

Faculty Publications, Department of Statistics

Statistics, Department of

2006

\title{
Pregnancy rate and first-service conception rate in Angus heifers
}

J. Minick Bormann

Kansas State University

L. R. Totir

lowa State University

Stephen D. Kachman

University of Nebraska-Lincoln, steve.kachman@unl.edu

R. L. Fernando

lowa State University, rohan@iastate.edu

D. E. Wilson

lowa State University

Follow this and additional works at: https://digitalcommons.unl.edu/statisticsfacpub

Part of the Other Statistics and Probability Commons

Minick Bormann, J.; Totir, L. R.; Kachman, Stephen D.; Fernando, R. L.; and Wilson, D. E., "Pregnancy rate and first-service conception rate in Angus heifers" (2006). Faculty Publications, Department of Statistics. 53.

https://digitalcommons.unl.edu/statisticsfacpub/53

This Article is brought to you for free and open access by the Statistics, Department of at DigitalCommons@University of Nebraska - Lincoln. It has been accepted for inclusion in Faculty Publications, Department of Statistics by an authorized administrator of DigitalCommons@University of Nebraska - Lincoln. 


\title{
Pregnancy rate and first-service conception rate in Angus heifers ${ }^{1}$
}

\author{
J. Minick Bormann, ${ }^{* 2}$ L. R. Totir, $\dagger$ S. D. Kachman, $\neq$ R. L. Fernando, $\dagger$ and D. E. Wilson $\dagger$ \\ *Department of Animal Sciences and Industry, Kansas State University, Manhattan 66506; \\ $\dagger$ Department of Animal Science, Iowa State University, Ames 50010; and \\ $\$$ Department of Statistics, University of Nebraska, Lincoln 68583
}

\begin{abstract}
The objective of this project was to determine the genetic control of conception rate, or pregnancy percentage in Angus beef heifers. Producers from 6 herds in 5 states provided 3,144 heifer records that included breeding dates, breeding contemporary groups, service sires, and pregnancy check information. Two hundred fourteen sires of the heifers were represented; with 104 sires having less than 5 progeny, and 14 sires having greater than 50 progeny. These data were combined with performance and pedigree information, including actual and adjusted birth weights, weaning weights, and yearling weights, from the American Angus Association database. Heifer pregnancy rate varied from 75 to $95 \%$ between herds, and from 65 to $100 \%$ between sires, with an overall pregnancy rate of $93 \%$, measured as the percentage of heifers pregnant at pregnancy check after the breeding season. Pregnancy was analyzed as a threshold trait with an underlying contin-
\end{abstract}

uous distribution. A generalized linear animal model, using a relationship matrix, was fitted. This model included the fixed effects of contemporary group, age of dam, and first AI service sire, and the covariates of heifer age at the beginning of breeding, adjusted birth weight, adjusted weaning weight, and adjusted yearling weight. The relationship matrix included 4 generations of pedigree. The heritability of pregnancy and first-service conception rates on the underlying scale was $0.13 \pm 0.07$ and $0.03 \pm 0.03$, respectively. Estimated breeding values for pregnancy rate on the observed scale ranged from -0.02 to 0.05 for sires of heifers. Including growth traits with pregnancy rate as 2 -trait analyses did not change the heritability of pregnancy rate. As expected for a reproductive trait, the heritability of pregnancy rate was low. Because of its low heritability, genetic improvement in fertility by selection on heifer pregnancy rate would be expected to be slow.

Key words: beef cattle, fertility, genetics, pregnancy

(C2006 American Society of Animal Science. All rights reserved.

J. Anim. Sci. 2006. 84:2022-2025

doi:10.2527/jas.2005-615

\section{INTRODUCTION}

Reproduction is one of the most economically important traits in beef production. As in other livestock species, the heritability of reproductive traits tends to be low. Traditionally, management has been used to maximize herd reproductive efficiency. There has been a recent interest in selection for fertility traits. Heritability for pregnancy rate has been reported to range from virtually zero (Toelle and Robison, 1985; Morris et al., 1987; Mathiews et al., 1995) to over 0.20 (Doyle et al., 1996, 2000; Thallman et al., 1999). An Australian study of Brahman-Shorthorns divergently selected for

\footnotetext{
${ }^{1}$ The authors would like to acknowledge the American Angus Association for their help and the use of their data, and the producers who are cooperating with this project.

${ }^{2}$ Corresponding author: jbormann@ksu.edu

Received October 22, 2005.

Accepted March 21, 2006.
}

high and low pregnancy rate reported a difference in pregnancy rate of 0.12 between the high and the low line, indicating that selection on pregnancy percentage can improve fertility (Hetzel et al., 1989). The genetic correlation between yearling pregnancy rate and lifetime pregnancy rate has been reported as 0.92 (Morris and Cullen, 1994) and 0.97 (Mwansa et al., 2000).

A trait similar to pregnancy rate is first-service conception rate. This trait has an advantage over pregnancy rate because it separates those heifers that settle on the first breeding from those that take many breedings, or settle naturally. This is economically important because of the cost of semen, the labor involved in heat checking and breeding for multiple AI, and the difference in the quality and value between AI calves and natural calves. Also, heifers that get pregnant on the first breeding are going to calve earlier, giving them improved chances to breed back the following year. Dearborn et al. (1973) found a heritability of 0.22 for first-service conception rate in crossbred cattle. 
The objective of this project was to study the genetics of female fertility in Angus cattle, and develop EBV that will help producers identify and select animals with greater genetic merit for female fertility.

\section{MATERIALS AND METHODS}

In cooperation with the American Angus Association, producers from 6 herds in 5 states provided breeding information on 3,144 replacement heifers that were bred at least once. Each record included breeding dates, breeding contemporary groups, service sires, and pregnancy check information. All herds attempted at least $1 \mathrm{AI}$ on every heifer and utilized natural service for the remainder of the breeding season. Within a herd, the length of the breeding season was consistent for all heifers. Fetal ages at pregnancy check were used to determine whether a heifer conceived on the first AI attempt, or on a subsequent AI or natural service. Timing of the pregnancy check differed by farm, but it was generally 60 to $90 \mathrm{~d}$ after the end of the breeding season. Farms differed in their use and method of estrous synchronization, but within a contemporary group, all heifers were managed alike. Breeding data were merged with performance and pedigree information, including actual and adjusted birth weights, weaning weights, and yearling weights from the American Angus Association database.

In this data set, pregnancy percentage was analyzed by coding each individual heifer record as a success or failure for pregnancy at the end of the breeding season. Pregnancy may have been from first or subsequent AI, or from natural service. First-service conception rate was analyzed by coding each heifer record as a success or failure for becoming pregnant from the first AI. This was determined by fetal age at pregnancy check. In cases of unclear fetal age, calving date was used to determine which service resulted in pregnancy.

Unlike most performance traits, pregnancy percentage and first-service conception rate records are binary (success/failure) measurements. Genetic analysis was performed by the software package Matvec (Kachman and Fernando, 2002). A generalized linear animal model, using the relationship matrix, was fitted. This model utilized threshold theory to analyze the data (Gianola and Foulley, 1983). The animal model was used to take advantage of all pedigree information because all heifers were purebred and registered. This also allowed the results to be more directly comparable to other research, as most recent studies have used the animal model to analyze pregnancy (Evans et al., 1999; Doyle et al., 2000; Martinez-Velazquez et al., 2003). Standard errors were calculated by the delta method (Oehlert, 1992). Estimated breeding values were transformed from the underlying to the observed scale (Gianola, 1979).

Model fixed effects for pregnancy rate and first-service conception rate included contemporary group, age of dam, and first-service sire. Subsequent service sires
Table 1. Distribution of heifer records by herd ${ }^{1}$

\begin{tabular}{lc}
\hline \hline Herd & $\mathrm{n}$ \\
\hline 1 & 130 \\
2 & 224 \\
3 & 631 \\
4 & 235 \\
5 & 1,738 \\
6 & 181 \\
\hline
\end{tabular}

${ }^{1}$ The 6 herds represented in this data set were located in North Dakota, Kansas, Iowa, Oregon, and Virginia.

were not included because many heifers only had 1 AI attempt, and most of those that were received more than $1 \mathrm{AI}$ were bred to the same service sire. Covariates included heifer age at the beginning of breeding, adjusted birth weight (BRW), adjusted weaning weight (WW), and adjusted yearling weight (YW). These data were calculated by the American Angus Association, including adjustments for age of dam for BRW and WW, and age for all traits. All weights were included to account for the effect of growth rate of the heifers on conception, and to determine which, if any, measure of growth should be included in the model. The contemporary group used was that submitted to the association by the farms for weaning contemporary group of the heifer. The individual producers confirmed that these were the correct breeding contemporary groups. The relationship matrix included the heifers and 3 generations of pedigree.

Pregnancy rate was then combined with BRW, WW, YW, and yearling gain (YG) to perform four 2-trait analyses, using linear-threshold models. These models included fixed effects of contemporary group, age of dam, and first-service sire, the covariate of heifer age at the beginning of breeding for pregnancy rate, and the fixed effects of contemporary group and age of dam for the growth traits. For the bivariate models, environmental correlations between the threshold variables adjusted for growth traits were zero, and the residual variance of pregnancy was $\pi^{2} / 3$.

The 6 herds represented in this data set were located in North Dakota, Kansas, Iowa, Oregon, and Virginia. The distribution of records by herd is shown in Table 1. All herds were progressive purebred breeders with extensive use of AI. Because of this, herds were tied together by the use of popular, high-demand AI sires. Farm 5 sent records from 1994 to 2000; farm 3 sent records from 1996 to 2000, and the rest of the records were from 1999 and 2000.

A total of 214 sires was represented in the data set. Table 2 shows the number of records by sire. Of the sires with less than 5 daughters, there were 39 sires with 1 daughter, 22 sires with 2 daughters, 29 sires with 3 daughters, and 14 sires with 4 daughters. Of sires with more than 50 progeny, there were 3 with 50 to 59,3 with 60 to 69 , and 8 with more than 70 progeny. 
Table 2. Number of daughter records by sire

\begin{tabular}{lr}
\hline \hline Daughters & Sires \\
\hline$<5$ & 104 \\
5 to 9 & 43 \\
10 to 14 & 19 \\
15 to 19 & 14 \\
20 to 29 & 10 \\
30 to 39 & 7 \\
40 to 49 & 3 \\
$>50$ & 14 \\
\hline
\end{tabular}

\section{RESULTS AND DISCUSSION}

The performance of heifers used in this study was similar to breed average. Table 3 shows means, standard deviations, minimums, and maximums for actual and adjusted birth weight, weaning weight, and yearling weight and the yearling gain for the heifers. Angus averages for heifers born in 2000 for adjusted birth weight, weaning weight, and yearling weight were 34.9 , 258.0 , and $375.5 \mathrm{~kg}$, respectively (AAA, 2003).

Pregnancy percentage, was defined as the percentage of heifers pregnant at fall pregnancy check, and was $93 \%$. First-service conception rate is the percentage of heifers that became pregnant after the first AI service. The average first-service conception rate in this data set was $60 \%$.

Genetic analysis was performed on pregnancy percentage and first-service conception rate. Genetic variance and heritability of pregnancy percentage on the underlying continuous scale were $0.47 \pm 0.30$ and $0.13 \pm$ 0.07 , respectively. (Using the logistic function, residual variance on the underlying scale was $\pi^{2} / 3$.) This heritability was similar to the 0.14 found in Herefords (Evans et al., 1999), the 0.15 found in New Zealand Angus (Morris et al., 2000), and the 0.14 found across breeds (Martinez-Velazquez et al., 2003). In contrast, some literature estimates have been lower, at 0.06 (Toelle and Robison, 1985), 0.03 (Mathiews et al., 1995), 0.06 (Mathiews et al., 1995), 0.09 (Dearborn et al., 1973), 0.03 (Morris et al., 1987), and 0.04 (Morris and Cullen, 1994); and some have been greater, at 0.24 (Evans et al., 1999), 0.21 (Doyle et al., 2000), 0.24 (Doyle et al., 1996), and 0.28 (Thallman et al., 1999). Estimated breeding values on the observed scale (percentage of daughters pregnant) ranged from -0.02 to 0.05 for sires of heifers. This indicates that, although its heritability is low, some improvement in fertility could be made by selecting on heifer pregnancy rate.

The genetic variance and heritability of first-service conception rate were $0.11 \pm 0.09$ and $0.03 \pm 0.03$, respectively, which is lower than the heritability of 0.22 reported by Dearborn et al. (1973). Heifers in this study were managed under commercial conditions, whereas the Dearborn et al. (1973) study took place on a research station. It is possible that under commercial conditions, there was variable quality of heat detection and artificial insemination. The low heritability would indicate that the ability of a heifer to conceive on first AI service has very little to do with her genetics. Producers striving to improve this economically important trait should concentrate on improving environmental factors that affect first-service conception, such as nutrition and AI technique, among others. Genetic selection for firstservice conception rate would not be expected to be successful due to its low heritability. The estimated breeding values on the observed scale (percentage of daughters pregnant after first service) ranged from -0.01 to 0.02 for sires of heifers.

The lower heritability of first-service conception rate relative to pregnancy rate would indicate that environmental variation plays a greater part in the ability of a heifer to become pregnant from the first service. Expertise of the estrus detector and the AI technician influences first-service conception rate more than overall pregnancy rate because of natural service clean-up bulls. Heifers with good fertility that did not become pregnant from the first service because of poor estrus detection or insemination technique could still conceive to the clean-up bull and be pregnant after the breeding season.

The 4 different 2-trait analyses produced the same heritability for pregnancy percentage of $0.12 \pm 0.07$. Including the growth traits in a multitrait analysis was not different than including them as covariates in a single analysis for pregnancy rate. The genetic variances, residual variances of the linear traits, genetic covariances, and genetic correlations are shown in Table 4 . The heritabilities found for the growth traits are greater than the 0.33 for $\mathrm{BRW}$, and the 0.20 for WW and YG reported by the American Angus Association for the entire database (AAA, 2004). The program does not calculate standard errors on correlations, but the

Table 3. Means, standard deviation, minimums, and maximums for adjusted and actual growth characteristics of heifers ${ }^{1}$

\begin{tabular}{lcccrrr}
\hline \hline & Adjusted & Actual & Adjusted & Actual & Adjusted & \multicolumn{2}{c}{ Actual } \\
Statistic & BRW & BRW & WW & WW & YW & YW \\
\hline Mean & 37.2 & 35.8 & 259.9 & 243.1 & 361.5 & 360.1 \\
SD & 4.1 & 4.6 & 28.5 & 35.3 & 37.5 & 47.3 \\
Minimum & 22.2 & 19.0 & 141.5 & 118.8 & 260.3 & 254.0 \\
Maximum & 58.5 & 55.3 & 358.3 & 358.3 & 491.6 & 546.5 \\
\hline
\end{tabular}

${ }^{1} \mathrm{BRW}=$ birth weight in $\mathrm{kg}$; WW = weaning weight in $\mathrm{kg}$; and $\mathrm{YW}=$ yearling weight in $\mathrm{kg}$. 
Table 4. Genetic variances $\left(V_{g}\right)$, residual variances for linear traits $\left(V_{e}\right)$, heritabilities $\left(h^{2}\right)$, genetic covariances $\left(\operatorname{Cov}_{\mathrm{g}}\right)$, and genetic correlations $\left(\mathrm{r}_{\mathrm{g}}\right)$ between pregnancy rate and birth weight and growth characteristics of heifers ${ }^{1}$

\begin{tabular}{|c|c|c|c|c|}
\hline \multirow[b]{2}{*}{ Item } & \multicolumn{4}{|c|}{ Growth characteristic $^{2}$} \\
\hline & BRW & WW & YW & YG \\
\hline \multirow{2}{*}{$\mathrm{V}_{\mathrm{g}}$ (pregnancy) } & 0.44 & 0.46 & 0.44 & 0.45 \\
\hline & $(0.30)$ & $(0.30)$ & $(0.30)$ & $(0.30)$ \\
\hline \multirow[t]{2}{*}{$\mathrm{V}_{\mathrm{g}}$ (growth trait) } & 55.90 & $1,997.39$ & $1,571.94$ & 374.88 \\
\hline & $(7.76)$ & $(264.63)$ & $(203.13)$ & $(76.28)$ \\
\hline \multirow{2}{*}{$\mathrm{V}_{\mathrm{e}}$ (growth trait) } & 65.64 & $1,946.95$ & $1,693.57$ & 998.55 \\
\hline & $(5.38)$ & $(178.86)$ & $(139.62)$ & $(59.67)$ \\
\hline \multirow[t]{2}{*}{$\mathrm{h}^{2}$ (pregnancy) } & 0.12 & 0.12 & 0.12 & 0.12 \\
\hline & $(0.07)$ & $(0.07)$ & $(0.07)$ & $(0.07)$ \\
\hline \multirow[t]{2}{*}{$\mathrm{h}^{2}$ (growth trait) } & 0.46 & 0.51 & 0.48 & 0.27 \\
\hline & $(0.05)$ & $(0.05)$ & $(0.05)$ & $(0.05)$ \\
\hline \multirow{2}{*}{$\operatorname{Cov}_{g}$ (pregnancy, growth) } & 0.11 & 5.45 & 1.26 & -4.25 \\
\hline & $(0.94)$ & $(5.43)$ & $(5.03)$ & $(3.09)$ \\
\hline $\mathrm{r}_{\mathrm{g}}$ (pregnancy, growth) & 0.02 & 0.18 & 0.05 & -0.33 \\
\hline
\end{tabular}

large standard errors on the covariances indicate these correlations are not different from zero.

\section{IMPLICATIONS}

Although the heritability for pregnancy rate was low, as it is in most reproductive traits, the range of breeding values indicated that genetic progress could be made by selection. However, producers should recognize that selection for pregnancy rate does not imply an increase in calving percentage, or percentage calf crop weaned. Pregnancy percentage means a pregnant heifer, not necessarily a live calf. Unfortunately, the heritability for first-service artificial insemination conception rate was virtually zero. Producers must rely on environmental factors rather than genetics to make improvements in first-service conception to artificial insemination.

\section{LITERATURE CITED}

American Angus Association. 2004. Angus trait heritabilities and genetic correlations. Available: http://www.angus.org/sireeval/ heritabilities.html Accessed Mar. 13, 2004.

American Angus Association. 2003. AHIR average adjusted weights and measurements by year. Available: http://www.angus.org/ sireeval/ahir_ave.html Accessed Dec. 23, 2003.

Dearborn, D. D., R. M. Koch, L. V. Cundiff, K. E. Gregory, and G. E. Dickerson. 1973. An analysis of reproductive traits in beef cattle. J. Anim. Sci. 36:1032-1040.

Doyle, S. P., B. L. Golden, R. D. Green, and J. S. Brinks. 2000. Additive genetic parameter estimates for heifer pregnancy and subsequent reproduction in Angus females. J. Anim. Sci. 78:2091-2098.

Doyle, S. P., R. D. Green, B. L. Golden, G. L. Mathiews, C. R. Comstock, and D. G. LeFever. 1996. Genetic parameter estimates for heifer pregnancy rate and subsequent rebreeding rate in Angus cattle. J. Anim. Sci. 74(Suppl. 1):117. (Abstr.)

Evans, J. L., B. L. Golden, R. M. Bourdon, and K. L. Long. 1999. Additive genetic relationships between heifer pregnancy and scrotal circumference in Hereford cattle. J. Anim. Sci. 77:2621-2628.

Gianola, D. 1979. Heritability of polychotomous characters. Genetics 93:1051-1055.

Gianola, D., and J. L. Foulley. 1983. Sire evaluation for ordered categorical data with a threshold model. Genet. Sel. Evol. 15:201-223.

Hetzel, D. J. S., M. J. Mackinnon, R. Dixon, and K. W. Entwistle. 1989. Fertility in a tropical beef herd divergently selected for pregnancy rate. Anim. Prod. 49:73-81.

Kachman, S. D., and R. L. Fernando. 2002. Analysis of generalized linear mixed models with MATVEC. Proc. 7th World Congr. Genet. Appl. Livest. Prod. CDROM Commun. No. 28-04.

Martinez-Velazquez, G., K. E. Gregory, G. L. Bennett, and L. D. Van Vleck. 2003. Genetic relationships between scrotal circumference and female reproductive traits. J. Anim. Sci. 81:395-401.

Mathiews, G. L., R. D. Green, J. S. Brinks, B. L. Golden, R. M. Enns, and D. G. LeFever. 1995. Genetic parameters for conception rate to synchronized breeding in Angus cattle. Proc. West. Sec. Am. Soc. Anim. Sci. 46:217-219.

Morris, C. A., R. L. Baker, D. L. Johnson, A. H. Carter, and J. C. Hunter. 1987. Reciprocal crossbreeding of Angus and Hereford cattle 3. Cow weight, reproduction, maternal performance, and lifetime production. N. Z. J. Agric. Res. 30:453-467.

Morris, C. A., and N. G. Cullen. 1994. A note on genetic correlations between pubertal traits of males or females and lifetime pregnancy rate in beef cattle. Livest. Prod. Sci. 39:291-297.

Morris, C. A., J. A. Wilson, G. L. Bennett, N. G. Cullen, S. M. Hickey, and J. C. Hunter. 2000. Genetic parameters for growth, puberty, and beef cow reproductive traits in a puberty selection experiment. N. Z. J. Agric. Res. 43:83-91.

Mwansa, P. B., R. A. Kemp, D. H. Crews, Jr., J. P. Kastelic, D. R. C. Bailey, and G. H. Coulter. 2000. Selection for cow lifetime pregnancy rate using bull and heifer growth and reproductive traits in composite cattle. Can. J. Anim. Sci. 80:507-510.

Oehlert, G. W. 1992. A note on the delta method. Am. Stat. 46:27-29.

Thallman, R. M., L. V. Cundiff, K. E. Gregory, and R. M. Koch. 1999. Germplasm evaluation in beef cattle-Cycle IV: Postweaning growth and puberty of heifers. J. Anim. Sci. 77:2651-2659.

Toelle, V. D., and O. W. Robison. 1985. Estimates of genetic correlations between testicular measurements and female reproductive traits in cattle. J. Anim. Sci. 60:89-100. 